\title{
ENSEÑAR ATENCIÓN FARMACÉUTICA EN LATINOAMÉRICA
}

\author{
MANUEL MACHUCA GONZALEZ
}

\author{
GRUPO DE INVESTIGACION EN ATENCIÓN FARMACEÚTICA (CTS-131). UNIVERSIDAD DE GRANADA, ESPAÑA.
}

\begin{abstract}
.....Le ha dicho a uno de sus médicos que tiene problemas de insomnio y que, para reponterse, desearia dormir un dia entero, desde la medianoche de un sábado hasta las cuatro de la tarde del domingo, por ejemplo. El médico le ha recomendado primero un ansiolitico, una droga que le relaje los músculos y ahuyente las tensiones, pero él lo rechaza. $Y_{a}$ otras veces ha hecho el intento, le dice, y ha sido peor: en vez de decrecer, la ansiedad lo ha vuelto loco. Un hipnótico, eso es lo que le hace falta. Fenobarbital entonces, responde el médico, después de dudar un rato. Si no damos con la dosis que te conviene, podrias despertarte con dolores de cabeza y mareos. No quisiera que luego me lo reclames. Un hipnótico, insiste él. Al fin de cuentas, es sólo para una vez. No, tengo miedo a una reacción desfavorable de iu hîgado y tus riñones, le dice el médico. Me preocupa que pueda afectarte el miocardio. En todo caso, no te excedas de dos comprimidos antes de dormir, doscientos miligramos. Tampoco se te ocurra beber alcohol: ni una gota. El efecto va a ser más firme con el organismo limpio. ¿X si tomara tres veces eso?, pregunta él. Si quisiera caer desmayado y olvidar todo y echarme al cuerpo seiscientos miligramos, por ejemplo, ¿qué me podría pasar?. No te morirás, dice el médico, pero te costaria levantarte. Sufririas de vértigo, tu sueño se parecería al de las anestesias, seguramente vomitarías. El efecto no sería muy diferente, pero las consecuencias, inútilmente, te harian sufrir. No se te ocurrirá probar eso, ino?. Para qué, responde él. /......
\end{abstract}

TOMÁS ELOY MARTÍNEZ «El vuelo de la reina»

La Atención Farmacéutica está en toda su plenitud en esta premiada novela del escritor argentino, cuya acción se desarrolla en su país, durante los cercanos años de la crisis económica, antesala de la êpoca del "corralito".

La literatura con frecuencia expresa la realidad de la vida. En este texto, nos muestra las necesidades de las personas a las que servimos, las que usan medicamentos y nos ayuda a identificar cuál es el último sentido de nuestra profesión, poder ayudarles a que obtengan el máximo beneficio de ellos.

Los profesionales de la salud a veces no nos damos cuenta de que los medicamentos son algo más que unas entidades químicas con propiedades farmacológicas y olvidamos a quien los usa, sus vivencias y sus porqués. Parafraseando al filósofo español Ortega y Gasset, que dijo aquello de "yo soy yo y mis circunstancias", los pacientes tienen sus circunstancias, un pasado que les condiciona, visto tanto desde su historia clínica como de su educación, su trabajo o el entomo social que les rodea, sus experiencias personales, su estado anímico..., en definitiva, su vida. Por eso no podemos pensar en igualar a dos personas por el hecho de que toman el mismo medicamento, es una simplicidad demasiado frecuente por desgracia, entre los profesionales de la salud.
Todas y cada una de las diversas relaciones que establece un paciente con sus medicamentos, lo son en función de sus circunstancias, de modo que el cómo un paciente toma sus medicamentos, el porqué los solicita directamente en una farmacia o acude al médico, el cumplimiento que realice de una terapia farmacológica, no son sino respuestas a experiencias anteriores y a sus conocimientos sobre la salud, su entorno asistencial, los problemas y los medicamentos.

$Y$ esos conocimientos no se aprenden en la escuela, sino que los dan o debemos dar los profesionales que nos dedicamos a la salud, que nos preparamos en las Universidades, muchas de ellas públicas y financiadas por el Estado, o sea, por los mismos pacientes.

Por tanto, una de las muchas responsabilidades de los profesionales es la educación sanitaria de los pacientes, como única vía posible, aunque desgraciadamente no suficiente, para aumentar el nivel de salud de las personas.

Recuperando la historia anterior, observamos que el protagonista principal no es el médico, sino que es el paciente. El médico es un actor secundario, cuyo papel es la exposición individualizada, en lenguaje asequible y objetivo, de lo que puede esperar del medicamento que va a tomar. Se trata, pues, de 
formar e informar, y no de imponer al paciente lo que diga la más reciente publicación que aparezca en el New England Journal of Medicine, es decir, tener en cuenta las preferencias y expectativas del paciente, buscando su complicidad como eje absolutamente imprescindible para conseguir el éxito de la terapia farmacológica.

Así, el actor secundario, el médico, deja para el actor principal, el paciente, la decisión, hipnótico mejor que ansiolítico. $Y$ esto no significa perder responsabilidades, ni mucho menos eludirlas. Todo lo contrario, constituye el primer paso a la corresponsabilidad y participación conjunta en la consecución de un objetivo de salud compartido por ambos, y es una señal inequívoca de respeto absoluto y de empatía, bases imprescindibles para abrir las puertas a la confianza. Pacientes y profesionales deben partir de puntos comunes para conseguir los objetivos terapéuticos y para ello, el profesional debe «bajar de su pedestal» y escuchar. Recuerdo un proverbio chino escuchado a Robert Cipolle, uno de los padres de la Atención Farmacéutica: «Si tenemos dos oidos y una sola boca, es porque tenemos que escuchar el doble que hablar».

En nuestra historia, el médico informa al paciente sobre lo que puede esperar de bueno del medicamento, dormir relajadamente un día entero, tal y como lo desea; cómo lo debe usar, no mezclarlo con alcohol, no tomar más de la dosis prescrita. También le habla de los efectos secundarios que puede sentir, despertarse con dolor de cabeza y mareos. $Y$ hace una valoración positiva del equilibrio beneficio- riesgo, sopesando las ventajas descritas y los posibles inconvenientes, ya que no hay nada que sea inocuo y todo tiene sus pros y sus contras. En el ámbito de la Farmacoterapia, no hay ni más ni menos milagros que en otros entornos de la sociedad.

$Y$, por último, también realiza prevención e individualiza la situación en función del paciente que tiene delante. Descarta aquellos problemas de uso a largo plazo, como los que pudiesen afectar al hígado y los riñones del paciente, debido a que sólo lo va a usar una vez, pero sí hace un especial énfasis en otros problemas, fatales por dificilmente evitables, los de miocardio, teniendo en cuenta la historia clínica del paciente y sus antecedentes.

Es una pena que en una descripción tan perfecta sobre la realidad de la asistencia clínica, en Argentina o en Perú, en España o en Japón, no aparezca el farmacéutico que dispensó la prescripción y que debía haber realizado el seguimiento de los efectos del barbitúrico. Sin embargo, sí que aparecen las consecuencias sanitarias, legales y sociales derivadas de la ausencia de esa práctica, expresadas en el fallecimiento de la persona que lo toma, tras un, cómo no, novelesco desenlace. Y por supuesto que cuenta con la inestimable participación de otros pro- fesionales, como policias, médicos forenses, jueces y abogados. Si la Atención Farmacéutica fuera una práctica profesional aprendida en la Universidad, asimilada por los pacientes de manera natural y consustancial a la labor del farmacéutico, seguro que su protagonismo hubiera sido importante, aunque quizás este ejemplo no fuese el más adecuado para animar a mis colegas a cambiar la profesión.

Los objetivos de las enseñanzas en Farmacia son múltiples, pero tienen en la mayoría de Universidades un fin último, la búsqueda del conocimiento profundo del medicamento, en cada uno de los eslabones de la cadena del mismo, desde su investigación a su fabricación. Pero a veces por cultura, y otras por desconocimiento, ignorancia, prepotencia o desgaste personal o profesional, la mayoría de enseñanzas olvidan el eslabón más importante, aquél en el que los medicamentos y el paciente interactúan para restablecer, aliviar o ayudar a mejorar la salud de quien lo toma, fin último y que da sentido a una profesión como la nuestra.

Las últimas modificaciones que de los planes de estudio se han hecho en España, aunque siguen siendo insuficientes en calidad y cantidad, y sobre todo en visión de futuro y mirada a largo plazo, han mejorado este aspecto, aumentando asignaturas y créditos en Farmacoterapia, Farmacocinética y Farmacodinamia, todas ellas muy centradas en el medicamento. Sin embargo, todavía faltan asignaturas que nos ayuden a entender a quienes lo usan, como Psicología, Comunicación o Antropología, ciencias sociales, tan científicas éstas como cualquier rama clásica de las ciencias naturales, que nos ayudarian a entender que lo principal de nuestra actuación profesional no es el medicamento, sino la persona que se lo va a tomar. El gran fracaso de la Medicina actual, del que los farmacéuticos asistenciales debemos sentirnos parte, es no entender esto. Hemos llegado a elevados conocimientos de las herramientas a utilizar para dar salud, hemos diseñado sofisticados aparatos para diagnóstico, gestión y evaluación de terapias, se ha desarrollado de forma espectacular la Medicina Basada en la Evidencia.... pero nos hemos olvidado de las personas. De ahí que en el soberbio mundo occidental, en el momento que más recursos existen para tratar las enfermedades y mayor cobertura social para afrontar sus consecuencias económicas, tres de cada cuatro enfermos no consigan controlar sus problemas de salud, y más de la mitad no cumplen sus tratamientos. Y esto sin que ello sea debido a que haya aumentado el número de locos, aunque sí de depresivos, pero ésa es otra historia de la que merecería la pena hablar, la relación entre el ser y el tener, el dinero y la felicidad, como lo expresa el psiquiatra austriaco Víctor Frankl. Con lo que podemos concluir que, quizás, algo estemos haciendo mal. 
Es difícil entender esta incoherencia, porque básicamente el medicamento ha sido creado para curar enfermedades en pacientes y un experto en medicamentos no sólo debe ser un experto en farmacoterapia; debe ser un experto en conocer la idiosincrasia de cada paciente, debe ser un experto en prevenir, detectar y evaluar los resultados positivos y negativos en salud; debe ser experto en ayudar al cumplimiento terapéutico, en educar y entender al paciente, o, por qué no, en dejar ser educado también por él, incluso escucharlo.

No nos queda otro remedio que integrarnos y formarnos para una sociedad que nos necesita más allá de la línea del mostrador. Ser experto en medicamentos no sirve para nada si no nos involucramos en cada paciente, en cada una de sus circunstancias, si no somos capaces de ofrecer una mano; porque el medicamento por él sólo es un medio para conseguir salud y no un fin en sí mismo, llámese mercaderia, sustancia química o principio activo, como algunos nos quieren hacer creer.

Hay quien dice que la practica profesional la enseña la vida, que eso de lo que hablamos lo genera la experiencia, que la Universidad no está para ensenar la función asistencial, sino que tan sólo debe transmitir el sesudo conocimiento académico, islas del saber, de no se sabe para qué. Permítanme que esto sólo me lo crea a medias y que lo vea mucho más como una excusa, producto del inmovilismo en el que se instalan muchos profesionales de diversos ámbitos, académicos cn este caso, aunque también asis-tenciales y políticos, que se resisten a los cambios. Nuestra experiencia en España nos indica que los compañeros que aprenden de nuevo, paradójicamente lo tienen más fácil que los que llevan años trabajando. Es decir, no es la experiencia la que manda, como sería de forma natural en cualquier profesión.

Y es que la práctica del Seguimiento Farmacoterapéutico, el cambio de actitud y de enfoque que representa el nuevo movimiento de la Atención Farmacéutica, necesita romper esquemas, limar barreras y romper un muro mucho más aislante y resistente que el muro de Berlín, como podemos comprobar los que día a día nos enfrentamos a éste.

La enseñanza de la Atención Farmacéutica durante los estudios de licenciatura, reduciría el efecto de resistencia a las ideas preconcebidas y permitiría reconocer esta actividad como la práctica natural del farmacéutico, con lo cual mejoraria la actitud, el único valor absolutamente imprescindible e irrenunciable. Enseñar Atención Farmacéutica, mejoraría los conocimientos, las habilidades y reforzaría esa actitud, que sin duda será el eje principal en torno al que desarrollar la implantación de esta prắctica asistencial.
La Universidad debe formar profesionales preparados, para afrontar retos que abran nuevos horizontes y que permitan nuestra evolución, para continuar dando respuesta a las necesidades que hoy tiene la sociedad, $y$ tener los ojos bien abiertos para cuando estas necesidades cambien. Debe proporcionar habilidades para sembrar conocimientos útiles, debe crear la inquietud de querer evolucionar y debe generar la actitud que posibilite superar los obstáculos.

El futuro de una profesión pasa de forma inexorable por solucionar cuestiones a la sociedad a la que sirve. Y si la capacitación debe realizarse en las Universi-dades, éstas tienen por fucrza algo que decir, sea cual sea el origen de su financiación; las privadas porque si no, los profesionales que forman no entrarán en el mercado, y las públicas porque, además de esto, estarán estafando a la sociedad que las sustenta.

Los farmacćuticos de todo cl mundo estamos ante el reto, o mejor dicho en palabras de Hepler y Strand, ante la oportunidad y la responsabilidad, de transformar una profesión en un momento histórico de cambio, que pocas veces se da a lo largo de los siglos y para una tan antigua, la del farmacéutico, como la vida misma. Y esto es así en España, en la vieja Europa, en Estados Unidos, y también lo es en Latinoamérica.

Pocas veces se dan estos momentos de cambio, pero también pocas veces conseguir los cambios necesarios se puede lograr con algo tan barato y a la vez tan difícil de conseguir. El cambio que representa la Atención Farmacéutica no cuesta dinero, no necesita herramientas tecnológicas costosas y complejas, no hay que pagar la patente a nadie. Este cambio necesita únicamente ojos para ver y oídos para escuchar, levantar la mirada de los farmacéuticos hacia los ojos de los pacientes, intentar entenderlos y aplicar nuestros conocimientos adquiridos con la inestimable ayuda de un lápiz y un papel. La mayor dificultad para hacer el cambio reside en la caída del muro de Berlín que muchos profesionales tienen en su cerebro, que no les permite ver más allá de lo que ya ven, sin querer explorar lo desconocido, negando la existencia de todo lo que hay detrás de él. En todo caso, tal y como se dice en el libro Sopa de pollo para el alma, ,la gente que dice que no se puede hacer no debería interrumpir a quienes lo están haciendo".

El cambio es posible en Latinoamérica, y me permitiría decir que en pocos lugares como acá puede ser tan factible. En mi experiencia a lo largo de este continente he tenido la oportunidad de contactar con muchos farmacéuticos entusiastas y cnamorados de su profesión. Muchas Universidades cuentan con farmacias propias, en las que profesores y farmacéuticos podrian aprender juntos esta nueva prácti- 
ca con pacientes reales. Esto es imposible a día de hoy en España y una quimera intentar ni siquiera cambiarlo. Lo definiríamos como nuestro particular «muro de Berlín». Los profesores de las Facultades de Farmacia viven aislados de la realidad de la práctica profesional, o sea, de las necesidades de los pacientes, y pienso que esto no es así, o es más fácil que no sea así en Latinoamérica. Los sistemas educativos y de protección a la salud quizás sean superiores en España ahora, pero esto, que es una realidad negativa acá, puede ser aprovechado en positivo, como una oportunidad para contribuir al cambio necesario. Los sistemas liberalizados protegen poco a sus ciudadanos, pero son más ágiles para poder promover los cambios.

Mi experiencia personal en el proyecto que tengo el placer de coordinar en Bolivia, donde llevamos trabajando muchos farmacéuticos españoles, de los Grupos de Investigación en Atención Farmacéutica de las Universidades de Granada y de Sevilla, con colegas de allá, de la Universidad San Francisco Xavier y del mundo asistencial, del entorno hospitalario y comunitario, en el que estamos intentando cambiar juntos la profesión, me hace pensar que soñar un mundo mejor es posible, lo que sin duda constituye el primer paso necesario para hacerlo realidad, y que lo único que necesitamos es encontrar profesionales con amor a su profesión y el coraje necesario para cambiar. Gente que crea en las palabras de Victor Frankl en su libro El hombre en busca de sentido: «En realidad no importa que no esperemos nada de la vida, sino si la vida espera algo de nosotros». O aquellas otras del senador por Minnesota Paul Wellstone, que murió en plena campaña electoral: «Algunas veces las únicas personas realistas son los soñadores».

Por eso el reto en Latinoamérica es doble. Existe una oportunidad de transformar una profesión mediante cambios para los que el dinero no va a ser un obstáculo, y además el entorno social, tan perjudicial para algunas cosas, favorece la implantación de estos nuevos procesos en la realidad docente y asistencial.

Por tanto, tan sólo queda, que no es poco, dejar de lamentarse y de justificarse, y que las personas implicadas, cada una en su puesto, estén dispuestas a derribar nuestro farmacéutico "muro de Berlín", que por supuesto que, como todos los muros artificiales y que coartan la libertad personal, va a caer, probablemente de forma tan rápida e inesperada como lo fue aquél. Y cada cual debemos decidir dónde queremos estar y cómo queremos participar en los momentos que se avecinan. Podemos ser avestruces que escondamos la cabeza ante los cambios que sin duda van a llegar, podemos ponerle puertas al campo o diques al mar, para evitar que lo inevitable aparez$\mathrm{ca}$, o podemos ir junto a otros farmacéuticos de todo el mundo, y esta vez no poniendo nuestro "grano de arena", sino más bien quitándolo y empujando para contribuir de forma activa a la caida del «muro" que simboliza nuestro aislamiento profesional.

De ahí que pediría que aquél que se sienta con fuerza para participar en el cambio lo haga, pero que aquí necesitamos gente que sea generosa, para compartir conocimientos, humilde, para reconocer que todavia queda mucho por aprender siempre, ya que lo importante es, como dijo Einstein, hacerse siempre preguntas $y$, necesitamos, por qué no, gente idealista, para pensar que podemos contribuir a mejorar nuestra profesión, y que mejorándola también estaremos contribuyendo, esta vez sí poniendo nuestro "grano de arena", a un país más justo.

No me cabe duda de que en Latinoamérica, donde los recursos y el acceso a la salud constituye un reto de los gobiernos, la Atención Farmacéutica representa una oportunidad y una responsabilidad para todos los que nos sentimos moral o formalmente implicados en su implantación, para así aportar una mayor eficiencia a los presupuestos empleados en la salud y contribuir a que más personas puedan acceder a un derecho irrenunciable del ser humano del siglo XXI. Hay que romper esquemas y entender que el derecho a la salud y a la educación están por encima de todos los derechos, incluso sobre el derecho de patente. $Y$ en esto no existe el tér mino medio. Hay que luchar contra la mediocridad sanitaria, contra la inexistente globalización de la salud y contribuir a romper las actitudes que pongan freno a actividades que contribuyan a mejorar los sistemas de atención sanitaria.

$Y$ quisiera finalizar con un texto de un escritor universal de nuestro pasado común, Miguel de Cervantes, en la muerte del Quijote:

"Perdóname amigo, la ocasión que te he dado de parecer loco como yo, haciéndote caer en el error en que yo he caído, de que hubo $y$ hay caballeros andantes en el mundo.»

«iAy!, respondió Sancho, llorando, no se me muera vuestra merced, señor mí, sino tome mi consejo y viva muchos años; porque la mayor locura que puede hacer un hombre en esta vida es dejarse morir, sin más ni más, sin que nadie le mate, ni otras manos le acaben que las de la melancolía....» 